\title{
A General Factor of Personality (GFP) in the Personality Disorders: Three Studies of the Dimensional Assessment of Personality Pathology — Basic Questionnaire (DAPP-BQ)
}

\author{
J. Philippe Rushton,' Paul Irwing ${ }^{2}$ and Tom Booth ${ }^{2}$ \\ ' Department of Psychology, University of Western Ontario, Canada \\ ${ }^{2}$ Manchester Business School, University of Manchester, United Kingdom
}

W used structural equation modeling to test the hypothesis that a General Factor of Personality (GFP) occupies the apex of the hierarchy of personality disorders in three validation samples of the Dimensional Assessment of Personality Pathology Basic Questionnaire (DAPP-BQ). In a general population sample $(N=942)$, we found a GFP explained $34 \%$ of the variance in four first-order factors and $33 \%$ of the variance in all 18 scales. In a twin sample ( $N=1,346)$, a GFP explained $35 \%$ of the variance in four first-order factors and $34 \%$ of the variance in all 18 scales. In a clinical sample $(N=656)$, a GFP explained $34 \%$ of the variance in four first-order factors and $30 \%$ of the variance in all 18 scales.

Keywords: General Factor of Personality, GFP, Diagnostic and Statistical Manual, DSM, Dimensional Assessment of Personality Pathology, DAPP-BO

A recent hypothesis is that a General Factor of Personality (GFP) occupies the apex of the hierarchy of the personality disorders in the same way that it organizes nonclinical personality traits and as $g$, the general factor of mental ability, organizes cognitive abilities (Rushton et al., 2008). Individuals high on the GFP are characterized as altruistic, agreeable, relaxed, conscientious, sociable, and intellectually open, with high levels of wellbeing, satisfaction with life, selfesteem, and emotional intelligence. Those with low scores on the GFP are socially less efficient and more likely to suffer a personality disorder. Because the GFP defines a clear positive pole and a clear negative pole, it is conjectured to have evolved as a result of evolutionary selection for socially adaptive traits that facilitate performance across a wide range of contexts. The main alternative to an evolutionary interpretation of the GFP is that it is due to artifacts of evaluative bias and scale construction (Anusic et al., 2009; Ashton et al., 2009; Bäckström et al., 2009).

The GFP has been found across diverse inventories, samples, and procedures. The nonclinical inventories include the Big Five and Big Five alternatives, the California Psychological Inventory, the Comrey Personality Scales, the EAS Temperament Scales, the Guilford-Zimmerman Temperament Survey, the Hexaco Personality Inventory, the Hogan Personality Inventory, the Jackson Personality Inventory, the Multidimensional Personality Questionnaire, the Personality Research Form, the Temperament and Character Inventory, and the Trait Emotional Intelligence Questionnaire (Erdle et al., 2010; Irwing \& Rushton, 2010; Musek, 2007; Rushton et al., 2008; 2009; Rushton \& Irwing, 2008, 2009a, 2009b, 2009c, 2009d; Schermer \& Vernon, 2010; Veselka et al., 2009a; Veselka et al., 2009b; Zawadzki \& Strelau, 2010).

The largest study to find a GFP comprised a sample of 628,640 Internet respondents who completed the Big Five Inventory (Erdle et al., 2010). One study found the GFP was independent of method variance using a multitrait-multimethod analysis of self-, teacher-, and parent-ratings of 391 13- to 14-year-olds on the Big Five Questionnaire - Children (Rushton et al., 2009). Several cross-national twin studies have found $50 \%$ of the variance on the GFP is attributable to genetic influence and $50 \%$ to nonshared environmental influence, including from 322 pairs of twins in the United Kingdom, 575 pairs of 2- to 9-year-old twins in South Korea, 651 pairs of 14- to 30-year-old twins in Japan, and 386 pairs of 18- to 74-year-old twins in Canada and the United States (Figuerdo et al., 2004; Rushton et al., 2008, 2009; Veselka et al., 2009a, 2009b). The South Korean twin data showed the GFP had emerged by 2 - to 3-years of age (Rushton et al., 2008).

Inventories of the personality disorders also yield a GFP. Rushton and Irwing (2009c) found a general factor of maladjustment from the interscale correla-

Received March 29, 2010; accepted May 5, 2010.

Address for correspondence: J. Philippe Rushton, University of Western Ontario, London, Canada.E-mail: rushton@uwo.ca 
tions of the Minnesota Multiphasic Personality Inventory-2 $(N=2,600)$ that explained $49 \%$ of the variance in two second-order factors dubbed Internalizing and Externalizing in a model that went from the GFP to two second-order factors, to four higher-order factors, and then to all 10 scales. Rushton and Irwing (2009d) extracted a GFP from the Millon Clinical Multiaxial Inventory-III $(N=998)$, which accounted for $41 \%$ of the variance in two second-order factors, again identified as Internalizing and Externalizing, $31 \%$ of the variance in five firstorder factors, and $26 \%$ of the variance in all 24 scales. Rushton and Irwing (2009d) also found a GFP in a cross-validation study of the Personality Assessment Inventory $(N s=1,246,1,000)$ that accounted for $65 \%$ of the variance in Internalizing and Externalizing, $47 \%$ of the variance in five first-order factors, and $27 \%$ of the variance in all 18 scales. They also found a GFP in a combined clinical and general population sample $(N=455)$ from the Spanish validation of the Dimensional Assessment of Personality PathologyBasic Questionnaire (DAPP-BQ; Gutiérrez-Zotes et al., 2008). This GFP accounted for $61 \%$ of the variance in six first-order factors and $36 \%$ of the total reliable variance in all 18 scales.

The publication of the DAPP-BQ manual (Livesley \& Jackson, 2009) provided an opportunity for a more complete investigation of whether a GFP exists among the personality disorders. We examine the inter-scale correlations for three validation samples in a close approximation to the ideal strategy for model-testing outlined by Jöreskog (1993). Designated 'strictly confirmatory', the strategy is only rarely approximated. Prior theory and research point to the correctness of a single model, which is then tested in a representative sample and, if accepted, is then tested in other representative samples. If confirmed, it can be concluded the model is generalizable. For calibration purposes, we used the inter-scale correlations for the general population sample given in the DAPP-BQ manual $(N$ $=942)$. For validation we used those given for a twin sample $(N=1,346)$ and a clinical sample $(N=656)$.

\section{Method}

The Dimensional Assessment of Personality Pathology-Basic Questionnaire (DAPP-BQ) is a 290item self-report instrument with five response categories for each item that range from 1 (Strongly disagree) to 5 (Strongly agree) yielding 18 factors of personality disorder (Livesley \& Jackson, 2009; Livesley \& Larstone, 2008). The 18 primary scales of the DAPP-BQ are: Affective lability (unpredictable intense emotions; moody, irritable with low threshold for annoyance; impatient; exaggerates emotional significance of events); Anxiousness (readily feels fearful, worried, and tense); Callousness (lacks empathy and remorse; lacks guilt; looks down on people); Cognitive dysregulation (thoughts tend to become disorganized and confused when stressed; experiences feelings of depersonalization and unreality); Compulsivity (need for order, precision, and structure; excessive concern with details); Conduct problems (violates social norms and laws; violent and resorts to threats and/or intimidation when angry); Identity problems (fragmented and unstable self-image; feelings of emptiness and boredom); Insecure attachment (fears rejection and abandonment by significant others); Intimacy problems (avoids intimacy and attachment); Low affiliation (interpersonally distant; not very sociable; afraid of social situations); Narcissism (exaggerates achievements and abilities; preoccupied with fantasies of unlimited success; grandiose); Oppositionality (resists expectations of satisfactory performance of routine tasks; resents authority); Rejection (antagonistic and hostile to others; seeks to dominate and control others; judgmental and critical; fails to get things done on time); Restricted expression (does not show emotions; appears unemotional; avoids self-disclosure); Self-harm (deliberate self-damaging acts; frequent thoughts of suicide); Stimulus seeking (craves excitement and stimulation with little regard for consequences; needs variety; cannot tolerate the normal or routine; denies realistic danger); Submissiveness (subservient and unassertive; constantly looks to others for guidance and reassurance); Suspiciousness (mistrusts other people; hyper-alert to signs of trickery or harm; searches for hidden meanings in events; questions others' loyalty).

According to the DAPP-BQ manual, most of the 18 content scales may be grouped into four clusters: Emotional dysregulation (Affective lability, Anxiousness, Cognitive dysregulation, Identity problems, Insecure attachment, Oppositionality, and Submissiveness); Dissocial behavior (Callousness, Conduct problems, Narcissism, Rejection, and Stimulus seeking); Social Avoidance (Intimacy problems, Low affiliation, and Restricted expression); Compulsiveness (Compulsivity).

\section{Results}

The manual of the DAPP-BQ provides inter-scale correlations for three samples: a general population sample $(N=942)$; a twin sample $(N=1,346)$; and a clinical sample $(N=656)$. These correlations are set out in Tables 1 to 3, respectively. In the diagonal are the alpha coefficients, also from the manual, based on Ns of 196, 1,346, and 656, respectively (Livesley \& Jackson, 2009, p. 83).

The analysis was conducted using a combination of exploratory and confirmatory factor analyses using LISREL 8.72 (Jöreskog, 1993). There is no fully satisfactory answer to the question of best model fit. We rely partly on the simulations of $\mathrm{Hu}$ and Bentler (1998, 1999), which suggest the utility of the standardized root mean square residual (SRMSR), the root mean square error of approximation (RMSEA), and the non-normed fit index (NNFI). We adopted cut-off points of $\leq .05$ for the SRMSR, about .06 for the 


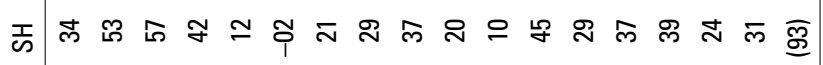

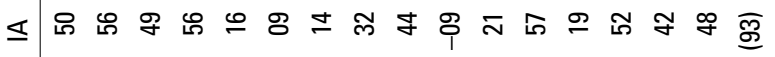

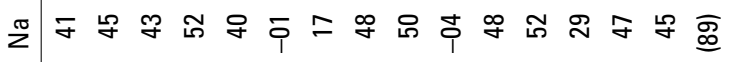

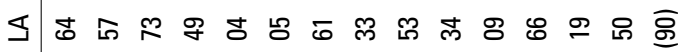

ら

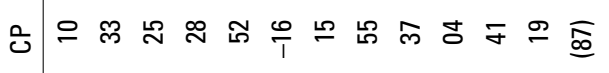

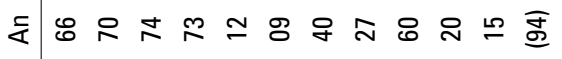

ஐ

유

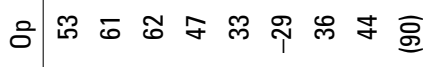

ฮำ

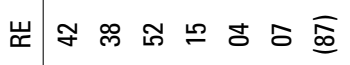

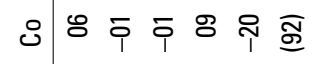

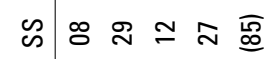

से \&

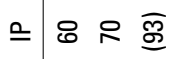

인요

号霝

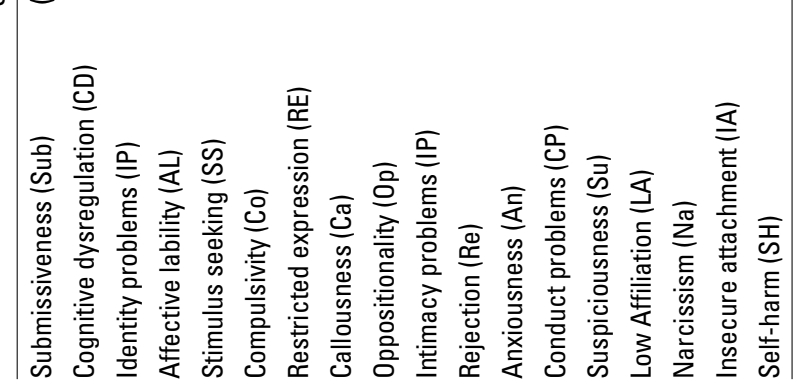




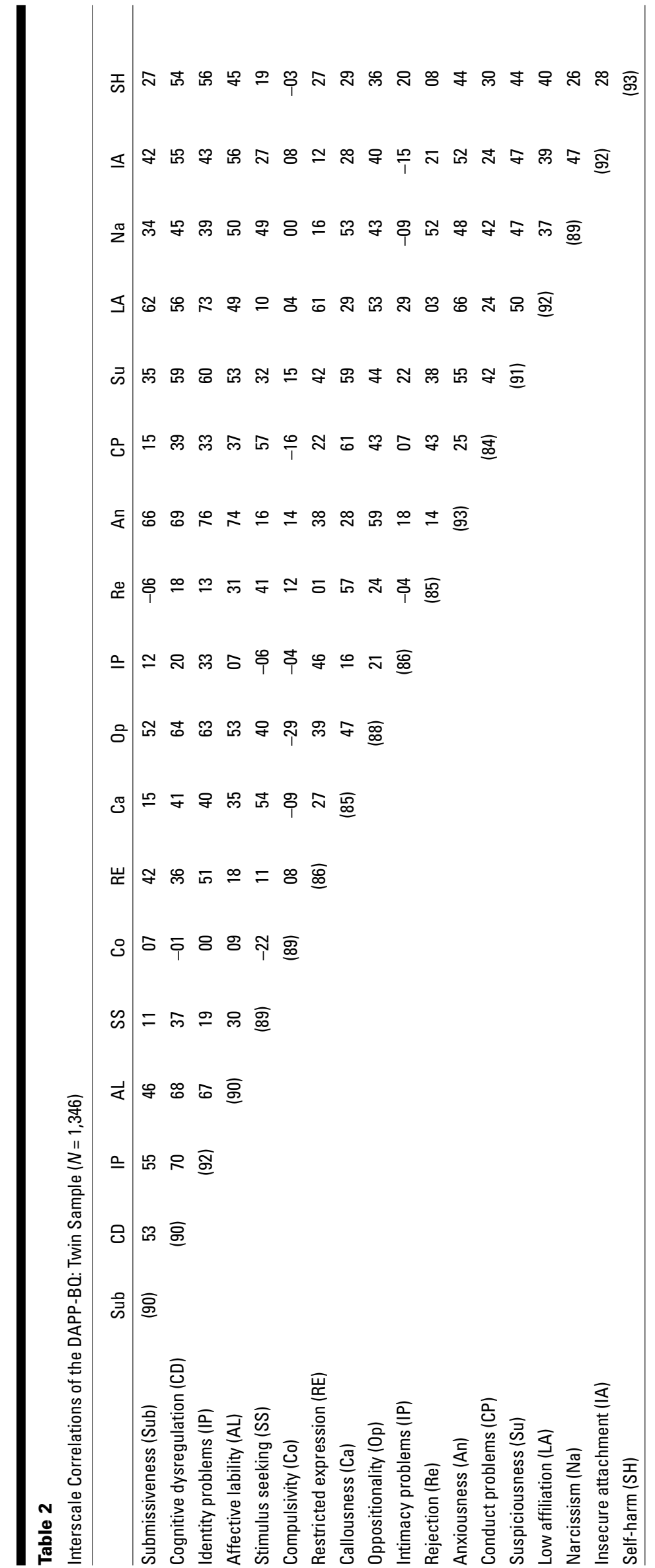




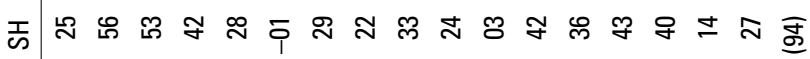

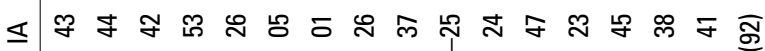

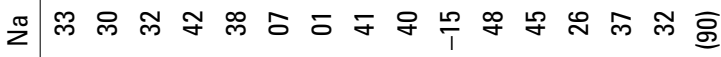

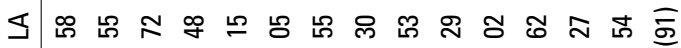

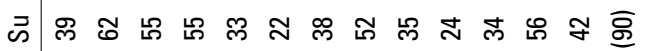

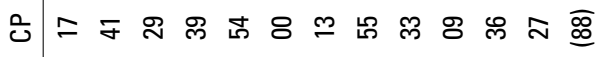

둔ำำ

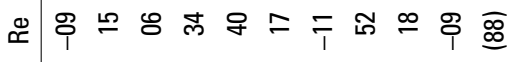

용ำ ஜ

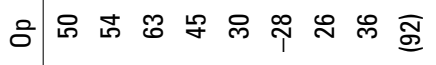

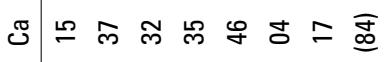

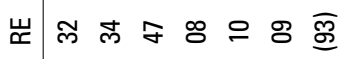

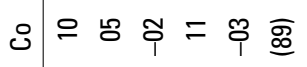

$\mathscr{\infty}$

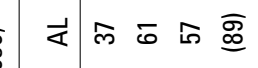

녀

○) ส

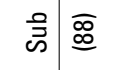

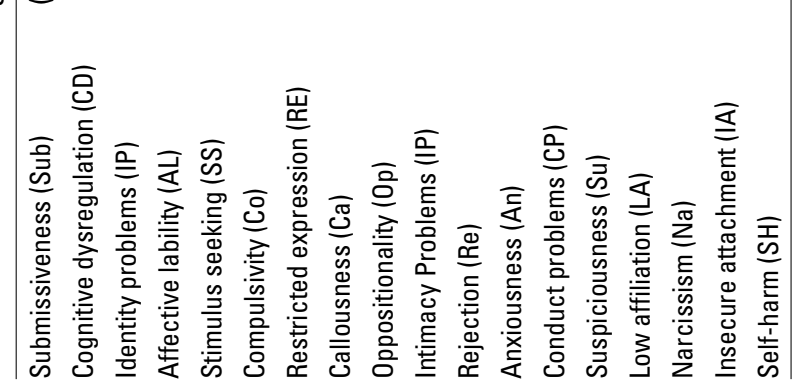


RMSEA, and $\geq .95$ for the NNFI, which conform to recent recommendations based on Monte Carlo simulation (Hu \& Bentler, 1998, 1999). We also take note of $\mathrm{Hu}$ and Bentler's two-index presentation strategy whereby a combination of an NNFI $\geq .96$ and an SRMSR $\leq .09$ minimize the sum of Type I and Type II error rates. In order to make direct comparisons between models, we examined chi-square differences following the recommendations of Jöreskog (1993), and in addition examined differences in all other reported indices, although there is no agreed metric for evaluating changes in fit indices. Since chi-square difference tests suffer many limitations, we treat these differences as indicators of comparative fit, rather than strict tests of the significance of differences.

Using the general population sample, we first carried out two strictly confirmatory analyses of the four factor solution presented in the test manual (Livesley \& Jackson, 2009, p. 90), and the six factor solution that Rushton and Irwing (2009d) had identified in their study of the Spanish DAPP-BQ. The first-order four factor solution indicated poor fit according to all fit indices $\left(\chi^{2}=2292.14 ; d f=110 ; P<.001 ;\right.$ SRMSR $=$ .089 ; RMSEA $=.15$; NNFI $=.88)$. Similarly, the firstorder six-factor solution provided acceptable fit according to the SRMSR, while the RMSEA and NNFI indicated poor fit $\left(\chi^{2}=1995.36 ; d f=118 ; P<.001\right.$; SRMSR $=.078 ;$ RMSEA $=.13 ; \mathrm{NNFI}=.89$ ).

In order to locate a plausible alternative model, the correlation matrix for the general population sample was subjected to a maximum likelihood exploratory factor analysis with Promax rotation in MPlus. Within exploratory factor analysis, there is no agreed upon method for establishing the correct number of factors to extract, and so we applied a number of procedures. Prior analyses had suggested between four and six factors account for the majority of variance in the primary scales of the DAPP-BQ. We used parallel analysis to assess the number of factors in the normative sample. Sample eigenvalues were taken from MPlus, with random comparison eigenvalues generated using O'Connor's (2000) SPSS program. The results of the parallel analysis supported a four-factor solution. ${ }^{1}$

Finally, four, five and six factor MPlus solutions were subjected to confirmatory factor analysis in LISREL 8.72. The six factor solution did not converge. The Akaike Information Criteria (AIC; Akaike, 1974) indicated the superiority of the four over the five factor solution $(\mathrm{AIC}=1865.73, \& 1937.55$, respectively). The initial four factor solution suggested moderate fit according to the SRMR and NNFI, and poor fit according to the RMSEA $\left(\chi^{2}=1767.7 ; d f=\right.$ 122; $P<.001 ;$ SRMSR $=.070 ;$ RMSEA $=.12 ;$ NNFI $=$ $.91)$. This model was further refined by allowing factor loadings and correlated errors as indicated by the modification indices $\left(\chi^{2}=797.1 ; d f=109 ; P<\right.$ $.001 ;$ SRMSR $=.046$; RMSEA $=.081 ; \mathrm{NNFI}=.96)$. While the SRMSR and NNFI were clearly in the region of close fit, the RMSEA was only indicative of moderate fit. These four factors closely resembled those reported in the test manual (Livesley \& Jackson, 2009) and were identically labeled: Emotional Dysregulation, Dissocial Behavior, Social Avoidance and Compulsivity. The first-order factor loadings from the general population sample are closely approximated by those shown in Figure 1.

Next, we tested for the possibility of the GFP, by directly modeling a single second-order latent variable. The resultant model, as presented in Figure 1, demonstrates adequate fit to the data according to the SRMSR and NNFI, while the RMSEA indicates moderate fit $\left(\chi^{2}=954.1 ; d f=113 ; P<.001 ;\right.$ SRMSR $=$ .061 ; RMSEA $=.087$; NNFI $=.95)$. In the general population sample, the GFP explained $33.9 \%$ of the variance in the four first-order factors and $32.7 \%$ of the variance in the 18 primary scales. Finally we crossvalidated the four factor model with a GFP using both the twin and clinical samples. In both cases, the model fit was similar to that found in the general population sample suggesting that the model was a suitable representation of both the twin $\left(\chi^{2}=1598.0 ; d f=113 ; P<\right.$ $.001 ;$ SRMSR $=.069 ;$ RMSEA $=.098 ;$ NNFI $=.94)$ and clinical $\left(\chi^{2}=809.7 ; d f=113 ; P<.001 ;\right.$ SRMSR $=$ .068 ; RMSEA $=.098$; NNFI $=.93$ ) data sets, although the RMSEA was undesirably high. In both the twin and clinical sample, the GFP explained a very similar proportion of variance to that found for the general population sample at $35.4 \%$ of the variance in the four first-order factors and $33.6 \%$ of the variance in the 18 primary scales for the twin sample, while the equivalent figures for the clinical sample were $34.3 \%$ and $30.4 \%$ respectively. Similarly, the parameter estimates in all three samples did not differ greatly (see Table 4).

\section{Discussion}

The three studies reported here confirm the hypothesis that a General Factor of Personality (GFP) occupies the apex of the hierarchical structure of the personality disorders in the Dimensional Assessment of Personality Pathology-Basic Questionnaire (DAPPBQ). We found a GFP that explained $34 \%$ of the variance in four first-order factors and $33 \%$ of the variance in all 18 scales for the US general population sample reported in the manual $(N=942)$. This solution cross-validated satisfactorily in both twin and clinical samples ( $\mathrm{Ns}=1,346,656$, respectively) in which the GFP explained a very similar $35 \%$ and $34 \%$ of the variance in four first-order factors and 34\% and $30 \%$ of the variance in all 18 scales. These results, showing a general factor of personality disorder in the US DAPP-BQ, join those found previously with the Minnesota Multiphasic Personality Inventory-2, the Millon Clinical Multiaxial Inventory-III, the Personality Assessment Inventory, and the Spanish version of the DAPP-BQ (Rushton \& Irwing, 2009c, 2009 d). However, the six-factor structure that Rushton and Irwing (2009d) found for the Spanish version of the DAPP-BQ did not generalize to the US 


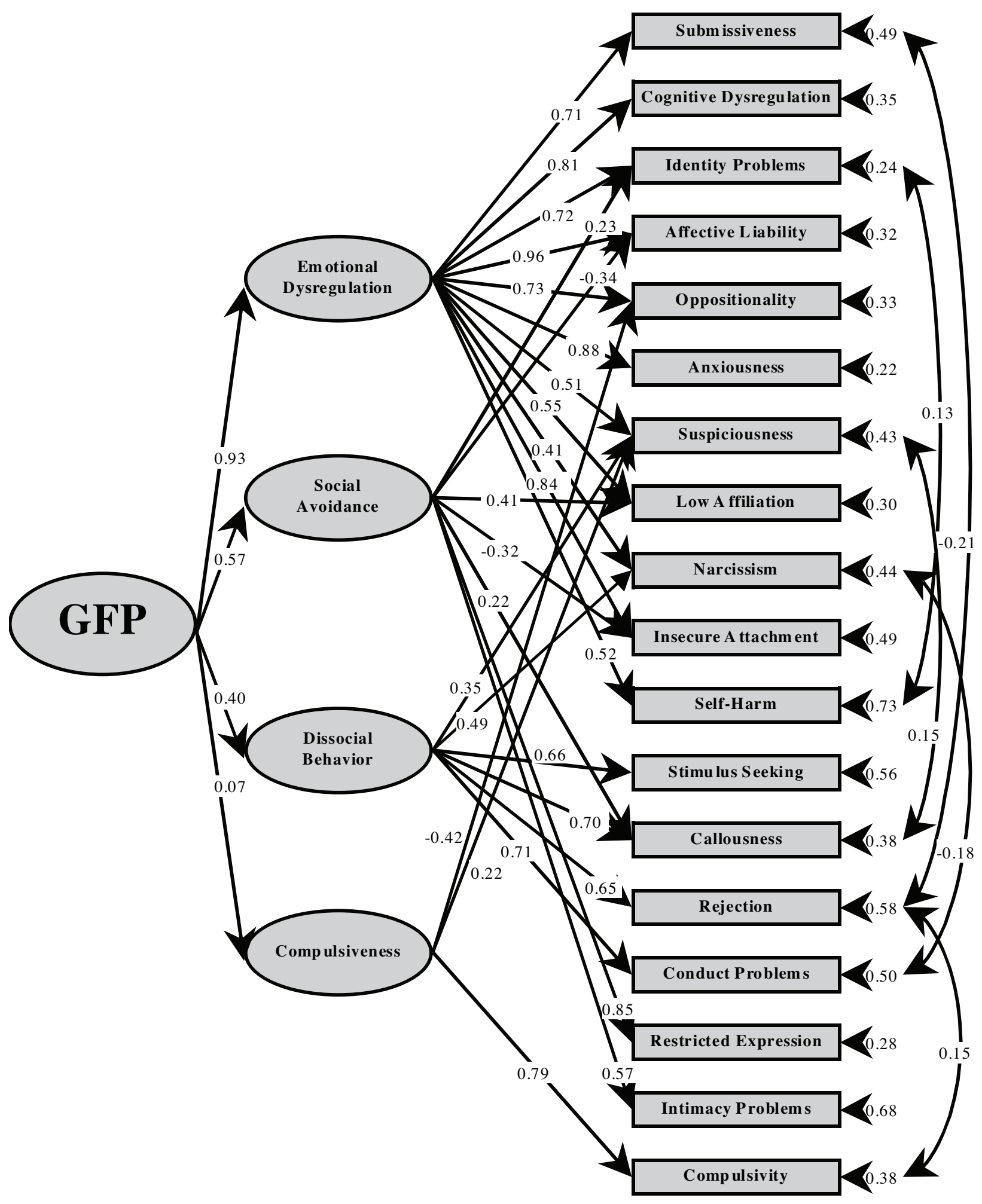

Figure 1

Second-order common factor structure of the Dimensional Assessment of Personality Pathology in the general population sample. 


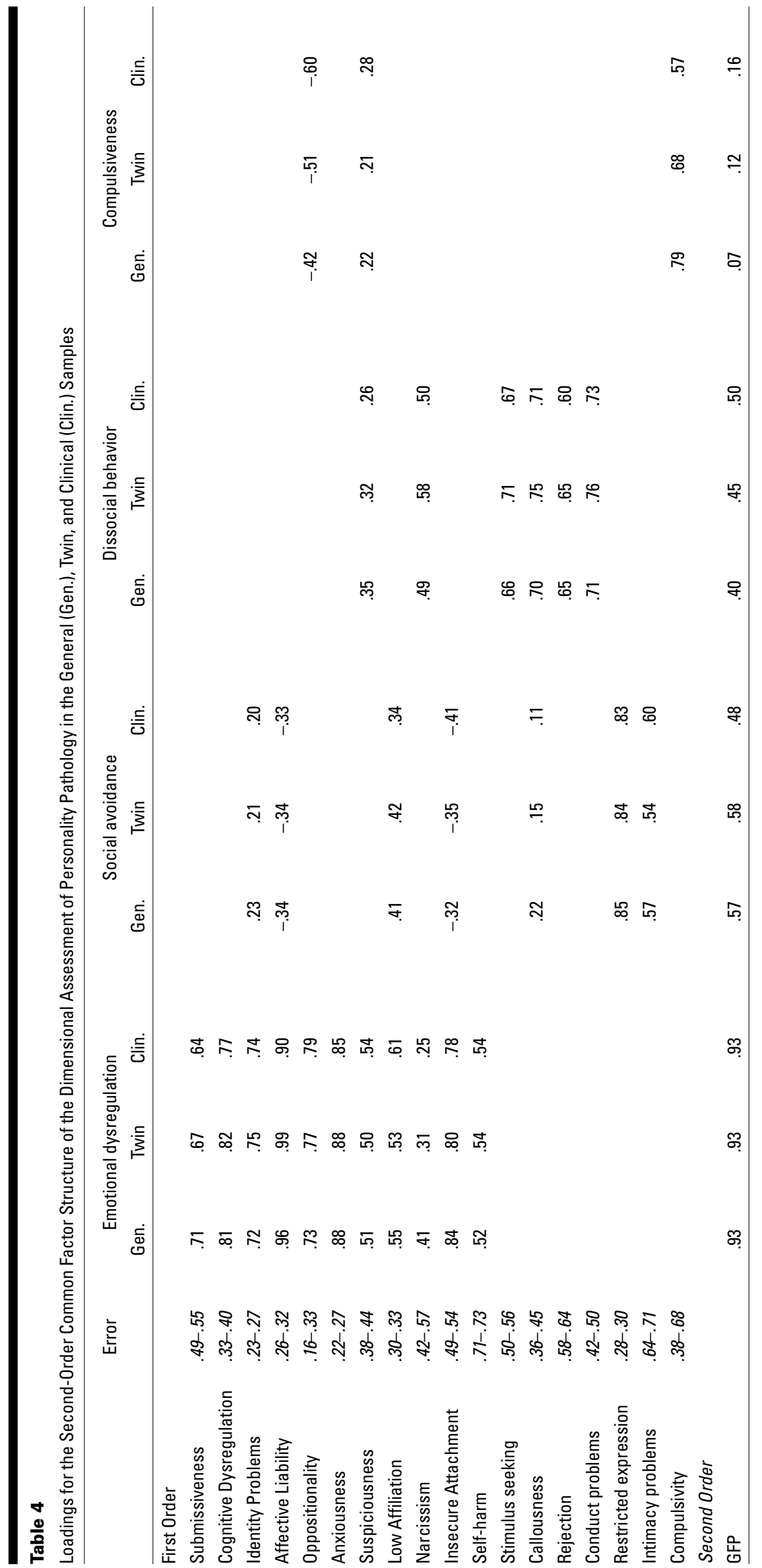


samples, which yielded the four-factor solution shown here (and in the manual; Livesley \& Jackson, 2009). It should also be noted that because the data in the twin sample violates the assumption of independence, the estimates of fit and standard errors for this sample must be biased. However, given the high level of similarity of estimates and fit statistics across all three samples, this bias must be relatively small.

Livesley and Larstone (2008) estimated that the DAPP-BQ captures between $29 \%$ and $63 \%$ of the variance of the personality disorders measured by the Fourth Edition of the American Psychiatric Association's Diagnostic and Statistical Manual (DSM-IV, 1994). The emergence of a general factor of mental disorder mirrors the highly correlated nature of the prevalence of DSM-IV disorders in the general population and comorbidity in general. The intercorrelations suggest a general factor of maladjustment and not a more specific problem such as demoralization. The intercorrelated nature of such measures has long been recognized and variously interpreted as comorbidity, social desirability, anxiety, ego resilience, or demoralization. Since a general factor of personality has been found in the non-clinical domain, the GFP might be better conceptualized as a veridical representation of human personality rather than as something specific to particular measurements.

The two second-order factors of Internalizing and Externalizing that Rushton and Irwing (2009c, 2009d) found in the Millon Clinical Multiaxial Inventory-III, the Minnesota Multiphasic Personality Inventory-2, and the Personality Assessment Inventory, were not found in the current analysis of the DAPP-BQ, which gave rise to the GFP directly from the four secondorder factors (Figure 1). Nor had Internalizing and Externalizing been found in Rushton and Irwing's (2009d) previous analysis of the Spanish DAPP-BQ, in which six first-order factors gave rise to the GFP. It therefore needs to be emphasized that the hierarchy of personality, on which the GFP sits atop, can be comprised of varying numbers of factors at the first-order level from as few as two to eight or more, and the traits comprising them can be expected to alter depending upon the composition of the inventory.

The compulsiveness factor shows only a small loading on the GFP varying from .07 to .16 across the three samples. However, a very common problem is that many primary scales intended to measure personality are multidimensional, which biases the covariance structure between the scales. Specifically, in the current study, Compulsiveness was primarily identified by the Compulsivity facet level scale, and inspection of its item content suggests that this is comprised of Conscientiousness in addition to the target trait. It seems likely that these components cancel out resulting in the observed low loading of Compulsiveness on the GFP. However, this and the above noted variations should not affect the nature of the GFP. Any measure of personality will include spe- cific variance as well as GFP variance. Consequently, although a GFP will be extracted from any number of broad sets of personality dimensions, the structure of the lower-order factors will depend on the particular scales comprising the inventory. Nonetheless, there is nothing vague about the GFP. Quite the contrary; it is by definition the most internally consistent linear combination of all traits. Its location at the apex of the hierarchy should be almost completely fixed in any large data set.

The twin data used to extract a GFP in Table 2 was not in a form that permitted a behavior genetic analysis. However, those data have been analyzed previously at a number of different levels, including the 18 primary and 4 higher-order factors depicted in Figure 1, as well as in combination with the Big Five (Jang \& Livesley, 1999; Livesley \& Jang, 2008). At each level, almost all the variance is explained by both genetic and non-shared environmental factors, as too, are the relations among the factors. Genetic continuity was also found between the normal and disordered traits. Since other evidence shows that the GFP is largely a genetic factor (Figueredo \& Rushton, 2009; Figueredo et al., 2004; Rushton et al., 2008, 2009; Veselka et al., 2009a, 2009b), future research might examine whether a GFP can be extracted directly from a genetic covariance matrix of the personality disorders, as well as whether a GFP found in the personality disorders is the same GFP found in normal personality (cf. Irwing \& Rushton, 2010).

The explanation we favor for the GFP is that, like $g$, it arose through evolutionary selection for adaptive traits that facilitate performance across a wide range of contexts (Figueredo \& Rushton, 2009; Rushton et al., 2008). The main alternative to evolutionary selection for the GFP is that it arises from artifacts of evaluative bias and scale construction (Anusic et al., 2009; Ashton et al., 2009; Bäckström et al., 2009). Since most studies of the GFP have used self-report measures, it can be argued that the results merely reflect response biases such as social desirability, selfdeception, and other self-referencing orientations (Edwards, 1957; Paulhus \& John, 1998). For example, Edwards (1957) showed that personality scales correlate with social desirability ratings made by judges, who agree with each other on what is socially desirable even when they come from different countries, varied walks of life, and different age levels.

However, the evidence that evaluative bias accounts for the GFP is weak and inconclusive. For example, studies find the GFP is extracted just as robustly from peer-ratings as it is from self-reports (Rauthmann \& Kolar, 2010; Rushton et al., 2008; Zawadzki \& Strelau, 2010). Other studies have failed to find direct evidence of social desirability effects. Although social desirability scales such as the Marlowe-Crowne, the Eysenck Lie, and Social Desirability from the Personality Research Form correlate positively with components of the GFP, the GFP remains intact after 
partialing out their effects (Erdle \& Rushton, 2010; Rushton \& Erdle, 2010; Schermer \& Vernon, 2010). Similarly, although Anusic et al. (2009) postulated that high self-esteem creates a 'halo effect' and correlates with the Big Five and the Big Two, the Big Two remained intact and gave rise to the GFP when SelfEsteem was partialed out (Erdle et al., 2009; Erdle et al. 2010). A GFP has also been extracted from inventories that selected items explicitly to minimize social desirability such as the Jackson Personality Inventory and Personality Research Form (Irwing \& Rushton, 2010; Schermer \& Vernon, 2010).

The existence of the general factor of personality does not invalidate the utility or theoretical importance of lower-order factors. No single factor can explain all manifestations of complex behavior. For example, the tests analyzed in this paper emphasize primary traits as the major focus of assessment because this is the level seen to be most appropriate for clinical research and intervention. Most interventions seek to change or modulate behaviors associated with primary traits rather then changing global personality disorder or secondary traits. Therefore it is a pragmatic question which level provides the best analysis for any particular situation.

\section{$\overline{\text { Endnote }}$}

1 In parallel analysis eigenvalues from the actual data and random data are compared. Factors are retained when the actual eigenvalue is greater than the randomly generated eigenvalues. The first six eigenvalues were $7.27,2.89,1.52,1.30,0.89$ and 0.66 in the actual data, with the first six random eigenvalues being $1.29,1.23,1.19,1.16,1.07$ and 1.05 .

\section{References}

American Psychiatric Association (1994). Diagnostic and statistical manual of mental disorders (4th ed.). Washington, DC: American Psychiatric Association.

Akaike, H. (1987). Factor Analysis and AIC. Psychometrikia, 52, 317-332,

Anusic, I., Schimmack, U., Pinkus, R. T., \& Lockwood, P. (2009). The nature and structure of correlations among Big Five ratings: The halo-alpha-beta model. Journal of Personality and Social Psychology, 97, 1142-1156.

Ashton, M. C., Lee, K., Goldberg, L. R., \& de Vries, R. E. (2009). Higher-order factors of personality: Do they exist? Personality and Social Psychology Review, 13, 79-91.

Bäckström, M., Björklund, F., \& Larsson, M. R. (2009). Five-factor inventories have a major general factor related to social desirability which can be reduced by framing items neutrally. Journal of Research in Personality, 43, 335-344.

Edwards, A. L. (1957). The social desirability variable in personality assessment and research. New York: Dryden.
Erdle, S., Gosling, S. D., \& Potter, J. (2009). Does selfesteem account for the higher-order factors of the Big Five? Journal of Research in Personality, 43, 921-923.

Erdle, S., Irwing, P., Rushton, J. P., \& Park, J. (2010). The general factor of personality and its relation to selfesteem in 628,640 Internet respondents. Personality and Individual Differences, 48, 343-346.

Erdle, S., \& Rushton, J. P. (2010). The General Factor of Personality, BIS-BAS, expectancies of reward and punishment, self-esteem, and positive and negative affect. Personality and Individual Differences, 48, 762-766.

Figueredo, A. J., \& Rushton, J. P. (2009). Evidence for shared genetic dominance between the general factor of personality, mental and physical health, and life history traits. Twin Research and Human Genetics, $12,555-563$.

Figueredo, A. J., Vásquez, G., Brumbach, B. H., \& Schneider, S. M. R. (2004). The heritability of life history strategy: The $K$-factor, covitality, and personality. Social Biology, 51, 121-143.

Gutiérrez-Zotes, J. A., Gutiérrez, F., Valero, J., Gallego, J., Baillés, E., Torres, X., Labad, A., \& Livesley, W. J. (2008). Structure of personality pathology in normal and clinical samples: Spanish validation of the DAPPBQ. Journal of Personality Disorders, 22, 389-404.

Hu, L.-T., \& Bentler, P. M. (1998). Fit indices in covariance structural modeling: Sensitivity to underparametrized model misspecification. Psychological Methods, 3, 424-453.

Hu, L.-T., \& Bentler, P. M. (1999). Cutoff criteria for fit indices in covariance structure modeling: Conventional criteria versus new alternatives. Structural Equation Modeling, 6, 1-55.

Irwing, P., \& Rushton, J. P. (2010). Just one general factor of personality (GFP): Consistent results from four test batteries. Manuscript under review, Manchester Business School, University of Manchester, UK.

Jang, K., \& Livesley, W. J. (1999). Why do measures of normal and disordered personality correlate? A study of genetic comorbidity. Journal of Personality Disorders, 13, 10-17.

Jöreskog, K. G. (1993). Testing structural equation models. In K. A. Bollen \& J. S. Long (Eds.), Testing structural equation models (pp. 294-316). London: Sage.

Livesley, W. J., \& Jackson, D. N. (2009). Dimensional Assessment of Personality Pathology-Basic Questionnaire: Technical manual. Port Huron, MI: Sigma Assessment Systems.

Livesley, W. J., \& Jang, K. L. (2008). The behavior genetics of personality disorder. Annual Review of Clinical Psychology, 4, 247-274.

Livesley, W. J., \& Larstone, R. M. (2008). The dimensional assessment of personality pathology (DAPP). In G. J. Boyle, G. Matthews, \& D. H. Saklofske (Eds.), The Sage handbook of personality theory and testing: 
Vol. 2. Personality measurement and assessment (pp. 608-625). London: Sage.

Musek, J. (2007). A general factor of personality: Evidence for the Big One in the five-factor model. Journal of Research in Personality, 41, 1213-1233.

O’Connor, B. P. (2000). SPSS and SAS programs for determining the number of components using parallel analysis and Velicer's MAP test. Behavior Research Methods, Instruments and Computers, 32, 396-402.

Paulhus, D. L., \& John, O. P. (1998). Egoistic and moralistic biases in self-perception: the interplay of self-deceptive styles with basic traits and motives. Journal of Personality, 66, 1025-1060.

Rauthmann, J. F., \& Kolar, G. P. (2010). Implicit simplicity at low acquaintanceship: Evidence for a g-factor of personality in personality judgments. Personality and Individual Differences, 48, 522-526.

Rushton, J. P., Bons, T. A., Ando, J., Hur, Y-M., Irwing, P., Vernon, P. A., Petrides, K. V., \& Barbaranelli, C. (2009). A general factor of personality from multitrait-multimethod data and cross-national twins. Twin Research and Human Genetics, 12, 356-365.

Rushton, J. P., Bons, T. A., \& Hur, Y-M. (2008). The genetics and evolution of a general factor of personality. Journal of Research in Personality, 42, 1173-85.

Rushton, J. P., \& Erdle, S. (2010). No evidence that social desirability response set explains the general factor of personality and its affective correlates. Twin Research and Human Genetics, 13, 131-134..

Rushton, J. P., \& Irwing, P. (2008). A General Factor of Personality (GFP) from two meta-analyses of the Big Five: Digman (1997) and Mount, Barrick, Scullen, and Rounds (2005). Personality and Individual Differences, 45, 679-683.

Rushton, J. P., \& Irwing, P. (2009a). A General Factor of Personality (GFP) from the Multidimensional
Personality Questionnaire. Personality and Individual Differences, 47, 571-576.

Rushton, J. P., \& Irwing, P. (2009b). A General Factor of Personality in 16 sets of the Big Five, the GuilfordZimmerman Temperament Survey, the California Psychological Inventory, and the Temperament and Character Inventory. Personality and Individual Differences, 47, 558-564.

Rushton, J. P., \& Irwing, P. (2009c). A general factor of personality in the Comrey Personality Scales, the Minnesota Multiphasic Personality Inventory-2, and the Multicultural Personality Questionnaire. Personality and Individual Differences, 46, 437-442.

Rushton, J. P., \& Irwing, P. (2009d). A General Factor of Personality in the Millon Clinical Multiaxial Inventory-III, the Dimensional Assessment of Personality Pathology, and the Personality Assessment Inventory. Journal of Research in Personality, 43, 1091-1095.

Schermer, J. A., \& Vernon, P. A. (2010). The correlation between general intelligence $(g)$, a general factor of personality (GFP), and social desirability. Personality and Individual Differences, 48, 187-189.

Veselka, L., Schermer, J. A., Petrides, K. V., Cherkas, L. F., Spence, T. D., \& Vernon, P. A. (2009a). A general factor of personality: Evidence from the HEXACO model and a measure of trait emotional intelligence. Twin Research and Human Genetics, 12, 420-424.

Veselka, L., Schermer, J. A., Petrides, K. V., \& Vernon, P. A. (2009b). Evidence for a heritable general factor of personality in two studies. Twin Research and Human Genetics, 12, 254-260.

Zawadzki, B., \& Strelau, J. (2010). Structure of personality: The search for a general factor viewed from a temperament perspective. Personality and Individual Differences, 49, 77-82. 